\title{
SOFRIMENTO PSÍQUICO DENTRO DOS SISTEMAS MODERNOS DE GESTÃO SOB A PERSPECTIVA DA INFLUÊNCIA DO LÍDER
}

\author{
Adriano Pereira da Silva (UFBA) pereiras.adriano@gmail.com \\ Francisco Gaudêncio Mendonça Freires (UFBA) gaudenciof@yahoo.com
}

\section{Resumo}

No presente estudo, buscamos propor uma pesquisa orientada a partir da perspectiva existente do sofrimento psíquico dentro dos sistemas modernos de gestão sob a perspectiva da influência do líder e circunscrever os seus destinos, quando manifestado no trabalho. Foram realizadas pesquisas bibliográficas na qual culminou na estruturação de um plano de investigação pautado no tipo de pesquisa, a população que será observada e a coleta de dados, trazendo, assim, um plano orientado de inclinações pertinentes a conduta de liderança. Por conseguinte, constatamos a existência, na gestão do trabalho, de um processo de transformação do sofrimento e orientação a conduta de liderança. Partindo do pressuposto de que o sofrimento é uma reação do sujeito diante da diversidade da vida, transformá-lo em adoecimento parece constituir, portanto, uma estratégia de quebra da resistência na gestão do trabalho, cujo papel do líder perpassa pela observação e assertividade do seu próprio comportamento.

Palavras-Chaves: Influência do líder. Sistemas modernos de gestão. Sofrimento psíquico.

\section{Introdução}

Os sistemas modernos de gestão exigem indivíduos cada vez mais flexíveis e dispostos a encararem novos desafios. A ansiedade instala-se então em grande parte, como resposta à essa responsabilidade de assumir esse perfil e corresponder às exigências e padrões da produtividade. Essa questão se faz de fundamental importância em nossa sociedade atual que, regida pelas leis do capitalismo, instituem que pessoas afastadas deste modo de produção, fiquem a mercê de não garantir uma sobrevivência com o mínimo de bem-estar necessário.

Assim, estilo de liderança não é uma função da personalidade, visto que os melhores líderes escolhem de forma eficaz o seu estilo de liderança para se adequar a uma determinada situação. Assim, a questão norteadora deste trabalho é: Qual atuação de líder perante a influência para com sua equipe de trabalho mediante o atual sistema de gestão no qual exerce o surgimento do sofrimento psíquico?

A partir deste cenário, observamos como objetivo desta pesquisa é analisar as ferramentas aplicáveis para um líder influenciar sua equipe no ambiente de trabalho. Para tal, foram estabelecidos alguns objetivos específicos: i - Expor os conceitos de lideranças conhecidos; ii 
- Apresentar o impacto da liderança dentro da equipe de trabalho; iii - Verificar qual perfil de liderança propicia influência em sua equipe de trabalho; iv - Descrever quais os sintomas que indicam a presença do sofrimento psíquico no trabalho; v - Investigar o emprego de estratégias de enfrentamento utilizadas pelos trabalhadores.

Assim, o presente estudo pretende contribuir com a literatura existente no âmbito das pesquisas de expor um estudo estruturado sobre perfil de liderança e contemplar linhas de pensamento comuns e divergentes entre os autores sobre o tema de pesquisa ao passo de contribuir para consolidação das informações no que diz respeito a estratégias de melhoria dos conceitos encontrados.

Por conseguinte, o restante do trabalho está estruturado como segue: a sessão dois apresenta uma revisão da literatura acerca do perfil de liderança e tudo aquilo que the compete para conduzir influencia à sua equipe de trabalho; a terceira sessão descreve o método utilizado na pesquisa; a quarta sessão discute os resultados obtidos pelo modelo aplicado; e as considerações finais da pesquisa são apresentadas na sessão final.

\section{Revisão teórica}

A fundamentação teórica permite verificar o estado do problema sob a ótica da pesquisa. Assim, sustenta à análise dos conceitos e modelos que irão abordar a argumentação acerca dos aspetos inerente ao desenvolvimento do trabalho. Assim, nesta sessão, são apresentados conceitos, importância a formas de aplicáveis da liderança por meio contextualizado, abordando uma discussão teórica dos fundamentos difundidos.

\subsection{Sofrimento psíquico nas organizações}

A globalização e a ênfase no uso da tecnologia da informação configuram características atuais do mundo do trabalho. E com elas, procedimentos que visam a objetividade, são capazes de fornecer e garantir fácil solução para problemas técnicos. $\mathrm{O}$ mesmo, porém, não acontece em relação às pessoas. Não é possível encontrar manuais, ou qualquer outro recurso fornecido pelas ciências exatas, para os conflitos relacionados ao comportamento humano. Dessa forma, sem as simples soluções apresentadas aos impasses técnicos, as pessoas representam um grande desafio para os líderes. (BERGAMINI; TASSINARI, 2008). 
As empresas, na tentativa de estabelecerem padrões, buscam, em manuais de administração, uma abstração que não corresponde à prática real, pois, não consideram as diferenças individuais e tomam o comportamento humano como totalmente previsível, propondo tratamento igualitário a todos. Assim, dificultam o processo de reconhecimento dos conflitos psíquicos e suas consequências, quando na verdade, deveriam apresentar mudanças organizacionais nesse sentido. É indispensável que profissionais de recursos humanos adquiram uma postura que ultrapasse a meramente administrativa e seja capaz de identificar e reconhecer o mal-estar psicológico. (BERGAMINI e TASSINARI, 2008).

Segundo Margis at al (2003), a relação entre eventos estressores e o surgimento de sintomas da ansiedade, apesar de muito citada, apresenta-se pouco explorada nas pesquisas. Sabe-se, no entanto, que estressores como desavenças interpessoais, por exemplo, são consideradas na etiologia de transtornos de ansiedade com o aparecimento de sintomas até mesmo, anos antes do transtorno em si.

Diante dessas condições que levam a uma ansiedade, os trabalhadores desenvolvem defesas especificas e fundamentais para a sua sobrevivência no trabalho. Quando são muito eficazes, essas defesas são capazes de praticamente anular traços do medo no discurso do trabalhador, por isso, é preciso buscar pelos sinais indiretos. Frequentemente encontra-se o desprezo em relação ao risco, este sintoma, no entanto, se caracteriza apenas como uma fachada criada pela defesa. É importante ressaltar que a vivência do medo existe, porém, é contida pelos mecanismos de defesa. Em casos de ambientes em que os riscos são amplos como em construções civis, esses mecanismos de defesa atuam não somente de maneira individual, mas, o foco está no grupo.

Os equipamentos de proteção, por exemplo, estão para prevenir riscos, porém, eles representam a existência do perigo o tempo todo, e podem acarretar um aumento da ansiedade na realização das tarefas. Por vezes, trabalhadores arriscam-se em performances perigosas para alcançarem um bom desempenho e até mesmo o respeito do grupo, pois segundo Dejours (1949), “criar uma situação ou agravá-la é, de certo modo, dominá-la”. Essa dominação é frutos mecanismos de defesa que, conforme sito anteriormente, são indispensáveis, uma vez que: "A consciência aguda do risco de acidente, mesmo sem maiores envolvimentos emocionais, obrigaria o trabalhador a tomar tantas precauções individuais que ele se tornaria ineficaz do ponto de vista da produtividade.” (DEJOURS, 1949) 
Há a preocupação com a exploração desse mecanismo, uma vez que, as estratégias de mediação contra o sofrimento, adotadas pelo indivíduo, podem ser utilizadas por gestores, para direcionar as ações ao alcance de metas e altos índices de produtividade. Nesse sentido, “o trabalho não causa sofrimento, é o próprio sentimento que produz trabalho" (DEJOURS, 1993, p.13 apud MENDES,2007). Ao afirmar a necessidade de elaboração do trabalho por parte do trabalhador em um espaço público, a psicodinâmica assume um caráter não apenas teórico e de pesquisa, mas também de ação (MENDES, 2007).

Já em tarefas submetidas a cadências e ritmos predeterminados, o fenômeno da ideologia defensiva não acontece e o essencial da ansiedade é assumido individualmente, e considera-se que a ansiedade provém das relações hierárquicas. Nestes casos a supervisão mantém a ansiedade em relação ao rendimento de cada trabalhador, como é o caso de falas esperanças de promoções e bonificações, que visam manter o controle e garantir a produtividade (DEJOURS, 1949).

\subsection{Saúde mental e trabalho}

Dejours em sua obra "A loucura do Trabalho - Estudo de Psicopatologia do trabalho" (1949), reflete sobre relação saúde mental e trabalho tomando como questão central os fatores que podem colocar a vida mental do homem em perigo, levando em consideração a especificidade de cada ser.

Alguns fatos históricos são considerados fundamentais no entendimento da evolução da relação da saúde mental com o trabalho tal como é concebida atualmente. O século XIX, marcado pelo crescimento do capitalismo industrial, é palco de grandes mudanças fundamentais. A primeira delas está no êxodo da população rural para cidades, o que caracteriza as grandes concentrações urbanas, formadas na busca por trabalho. Este, por sua vez, atinge de doze a 16 horas por 0dia, explora crianças, oferece salários muito baixos e altos índice de acidentes no trabalho. Somados à esses aspectos estão: a falta de higiene, o esgotamento físico, a subalimentação e caracterizam o alto potencial de morbidade e mortalidade. Nesse período, portanto, a luta pela saúde significa a luta pela sobrevivência (AMARANTE, 2007). 
A situação somente começa a apresentar mudanças favoráveis aos trabalhadores quando as reivindicações operárias para essas condições, se tornam cada vez mais frequentes e organizadas alcançam um nível político. A redução da jornada de trabalho é a principal reivindicação que marca todo o século XIX e é seguida de outras reivindicações como: a proibição do trabalho infantil, proteção a mulheres, o direito ao repouso semanal (DEJOURS, 1949).

Até então a relação trabalho e vida mental é praticamente desconhecida. Na época, predomina a OCT (Organização Científica do Trabalho) caracterizada pelos princípios de Taylor. Importante ressaltar que, por Organização do Trabalho entende-se a divisão do conteúdo da tarefa de cada trabalho, considerando o sistema hierárquico, as relações de poder, as modalidades de comando e as responsabilidades.

\subsection{Perfil do líder}

A partir da Globalização e difusão da informatização, a competição e a concorrência entre as empresas elevaram-se a níveis jamais imaginados e tende a continuar a crescer em velocidade cada vez maior. Estes fenômenos demandam que as empresas tenham que melhorar e muito sua competitividade como condição de sobrevivência. Diante deste quadro, o ser humano passa a se constituir no mais importante recurso de uma organização. O importante agora, e daqui para frente, é ter pessoas que maximizem o uso do capital e que saibam gerar, desenvolver e aplicar conhecimentos, métodos e tecnologias, notadamente às relacionadas com o ser humano, de como tornar as pessoas motivadas para atingir os objetivos organizacionais (DA SILVA, 2011).

Diante deste contexto, é necessário que sejam bem recrutados, selecionados, ensinados e treinados, motivados, mantidos e envolvidos. Neste processo a presença de líderes é essencial para a organização, como um todo, pois nitidamente devem cuidar dos quatro impulsos emocionais básicos, mesmo que sejam limitados por normas organizacionais, assim, assumese uma postura que proporcione influência sobre a motivação geral quanto qualquer diretriz organizacional. Neste sentido, a figura 1 expõe em mais detalhe os motores da motivação, as alavancas que o gerente pode usar para manipulá-los e estratégias "locais" que podem melhorar a motivação, apesar de limitações organizacionais. 
Figura 1 - Impulsos

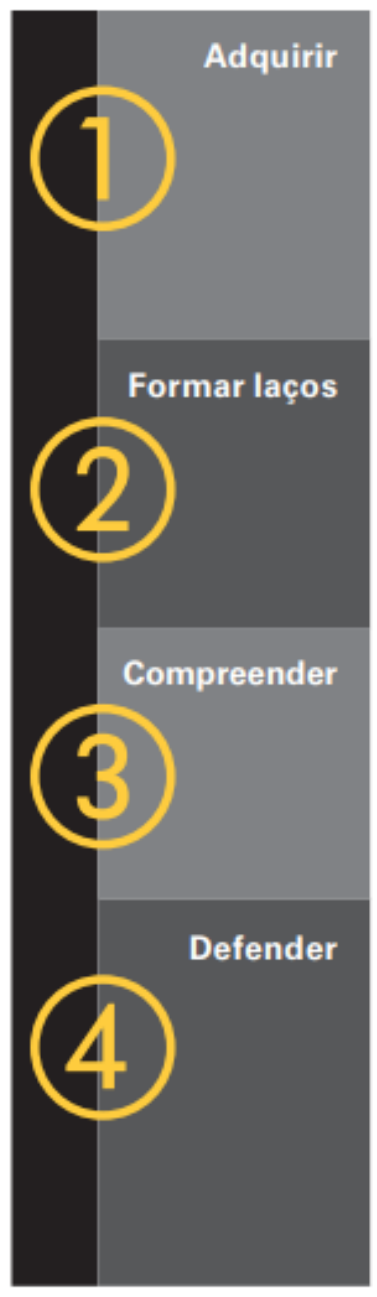

\section{Sistema de premiação}

Cultura

Desenho do trabalho

Processos de gestão de desempenho e alocação de recursos
- Diferenciar claramente quem tem bom desempenho de quem se sai mal ou é mediano.

- Vincular nitidamente recompensa ao desempenho.

- Pagar tão bem quanto as concorrentes.

- Promover confiança mútua e amizade entre colegas de trabalho.

- Valorizar colaboração e trabalho em equipe.

- Incentivar partilha de melhores práticas.

- Desenhar funçōes cujo papel seja distinto e importante na organização.

- Desenhar funçōes que tenham sentido e criem um senso de contribuição para a organização.

- Aumentar a transparência de todos os processos.

- Enfatizar caráter justo de processos.

- Conquistar confiança com a justiça e a transparência na hora de distribuir recompensas, tarefas e outras formas de reconhecimento.

Fonte: Adaptado de Wagner (2017)

Por conseguinte, Wagner (2017), explica que apenas um método simples pode avaliar sua equipe e fornecer informações que ajudarão os membros da equipe a melhorar seu desempenho é verificar os critérios de desempenho - É importante escolher critérios claros e não ambíguos como cumprir prazos, ficar dentro do orçamento ou lidar com a quantidade necessária de consultas diárias de cliente. Com critérios objetivos, não deverá ter problemas em fazer com que os membros da equipe concordem com sua avaliação.

Compartilhar comentários positivos - Quando se reunir com os membros da equipe, elogie suas conquistas. Esforçar-se para demonstrar onde a equipe excedeu os critérios de desempenho. Usar exemplos específicos e certificar-se de ser positivo, caso contrário, seus comentários podem parecer injustos ou desonestos. Tenha cuidado para não exibir favoritismo ao fazer elogios individuais. Compartilhar comentários de melhoria - Se a equipe não cumprir um dos critérios de desempenho, discuta como, quando e onde. Avaliar o desempenho geral - 
Consolidar comentários negativos e positivos em uma única avaliação de desempenho. Usar para ajudar os membros da equipe a compreenderem como as mudanças no desempenho afetarão as avaliações futuras. Buscar feedback - Membros da equipe podem discordar de sua avaliação ou adotarem uma postura defensiva. Ouvir cuidadosamente e permaneça neutro conforme eles respondem aos seus comentários. Você não precisa concordar com suas ideias e recuar em sua avaliação, mas você precisa ser objetivo, aberto e imparcial. Se não fizer isso, o desempenho de sua equipe será afetado. Definir diretrizes ou prazos para melhorias - Fazer um acordo com os membros da sua equipe sobre como seguir adiante. Juntos, elaborem um plano para implementar melhorias, juntamente com prazos realistas.

\section{Metodologia}

O presente artigo segue uma estrutura lógica de classificação, a saber: natureza, objetivos, abordagem e método. Quanto à natureza, esta pesquisa é considerada ou fundamental, pois está focada na melhoria de teorias científicas para melhoria da compreensão de fenômenos naturais, ou seja, refere-se ao estudo destinado a aumentar a base de conhecimento científico. Quanto ao objetivo, a pesquisa é descritiva por apresentar características de determinado fenômeno e o estabelecimento de relações entre variáveis de modo que possam ser envolvidos os usos de técnicas padronizadas de coleta de dados.

Sob o ponto de vista dos procedimentos adotados, partiu-se da concepção de Gil (2002), que ressalta a essencialidade de levantamento de dados e informações, na qual, a proposta do tema abordado permeou a estruturação de banco de arquivos, composto por documentos que contemplasse a parte teórica e dados históricos. O período de pesquisa foi dado no ano de 2019, durante o terceiro trimestre.

\section{Resultados e discussão}

A partir do perfil comportamental definido entre os grupos de trabalho, líderes eficazes criam uma visão que outras pessoas vão apoiar incondicionalmente sua equipe, mesmo, como supracitado, inserido em um contexto de sofrimento psicológico. De maneira simples, uma visão é uma descrição de um futuro alterado e aprimorado. Essa visão não precisa ser necessariamente grandiosa ou inovadora. Entretanto, é preciso que seja sensata e que motive outras pessoas a alcançá-la. 
Uma visão tem três importantes objetivos:

- Em primeiro lugar, ela esclarece a direção geral para o futuro: uma vez que as pessoas frequentemente confundem ou discordam sobre os caminhos que suas equipes, unidades ou organizações devem tomar, elas podem emperrar em indecisões. Ao estabelecer uma direção clara, uma visão ajuda as pessoas a tomar decisões e a seguir adiante com mais confiança.

- Em segundo lugar, uma visão motiva as pessoas a tomarem medidas na direção certa, mesmo que seja pessoalmente difícil: as alterações necessárias para apoiar uma visão geralmente não são fáceis. Geralmente, as pessoas são solicitadas a aprender novas habilidades rapidamente ou a trabalhar com recursos limitados por um período. Uma visão eficaz ajuda a superar a relutância das pessoas em fazer o que é necessário, oferecendo esperança e inspiração para o futuro.

- E por último, uma visão ajuda a coordenar de forma eficaz as ações de diferentes pessoas: se você estabelece uma visão clara, as pessoas ao seu redor geralmente entendem por si só o que elas devem fazer. Sem uma visão bem articulada para guiá-las, elas gastam um tempo valioso pedindo constantes orientações a outras pessoas.

Uma visão eficaz é de fundamental importância para liderar e motivar a equipe. Assim. Se torna importante comunicar a visão que possui de forma eficaz para as partes interessadas. Para tanto, comunicar essa ideia começa por analisar a partir da perspectiva de cada um dos envolvidos à medida que identifique qual seria a maior fonte de motivação e inspiração para fazê-los alcançar o resultado almejado. Ao difundir esse planejamento, a explicação pormenorizada do impacto dos benefícios do futuro alternativo sobre eles passar pela certificação de que a terminologia e os conceitos utilizados sejam facilmente compreendidos e associados por todos.

Em paralelo, um pré-requisito para a comunicação eficaz da sua visão é a credibilidade que é estabelecida com o público alvo. Credibilidade tem origem em dois fatores: qualificação e confiança. Ou seja, quando exerce o discernimento, provando que é bem informado sobre suas ideias e acumula exemplos de sucesso, as pessoas o veem como um especialista. Quando você é honesto, sincero e coloca os interesses dos outros à frente dos seus, você conquista a confiança das pessoas. Assim, a única maneira de edificar a credibilidade de que você precisa 
para fazer o seu público alvo acreditar - e acompanhar - a sua visão é estabelecer a fidedignidade e a qualificação.

Não obstante, em um mundo ideal, todas as pessoas na organização seriam inspiradas por sua visão e estariam dispostas a trabalhar para cumprir as suas metas finais. $\mathrm{Na}$ realidade, entretanto, provavelmente vai encontrar pessoas que não desejam seguir na mesma direção. Por mais que seja simplesmente ignorar essas pessoas, é dever do líder lidar com elas frente a frente. Caso essas pessoas não sejam abordadas, elas podem minar os esforços, reduzindo os níveis de produtividade e moral. Dessa, forma, ao tentar motivar funcionários obstinados, líderes inexperientes geralmente cometem o erro de esquecer que todas as pessoas têm diferentes ímpetos, valores e inclinações motivacionais. Eles entendem que se posicionarem sua perspectiva de uma certa maneira e utilizarem a linguagem correta, os funcionários problemáticos vão conseguir enxergar a lógica de seus pontos de vista. Infelizmente, esses tipos de esforços estão fadados ao fracasso. Portanto, para motivar funcionários problemáticos de forma bem-sucedida, deve-se descobrir quais são suas motivações inerentes.

Em contrapartida, situações inerentes ao ambiente organizacional corresponde muitas vezes em discussões. Por conseguinte, a principal função como líder de uma discussão é fazer com que sua equipe discuta o porquê e como certos conceitos se aplica a ela. Assim, a tarefa como líder de uma discussão é, muito mais do que ensinar: é incentivar a aprendizagem por meio da troca de experiências, desafios, dúvidas e pontos de vista. É provável a descoberta de que também faz parte do grupo de aprendizes, uma vez que, frequentemente, os líderes aprendem tanto com as equipes quanto as equipes aprendem com eles. Para tanto, procedimentos aplicáveis para esse cenário dessa contornado segue:

1. Realizar uma revisão do tema e do roteiro: Sua preparação deve incluir uma reflexão do propósito e do roteiro para a discussão que o acompanha. O roteiro apresenta questões para orientar a discussão e indica que respostas devem ser buscadas.

2. Refletir sobre sua equipe e adapte as questões: Considere a possibilidade de adaptar as questões sugeridas no roteiro, de forma a corresponder às preferências ou aos desafios específicos da equipe.

3. Considerar a possibilidade de formar uma parceria: Identificar a possibilidade de formar uma parceria com um colega, a fim de que possam liderar juntos uma discussão envolvendo 
as equipes de ambos. Esse recurso pode, de certa forma, tornar mais fácil a liderança da discussão e, além disso, cada equipe poderá se beneficiar de questões e insights trazidos pela outra equipe.

4. Aprimorar o ponto de vista: Antes da discussão, refletir sobre as próprias perspectivas quanto aos conceitos que pretende discutir. Deve-se sempre encorajar os participantes a compartilhar as perspectivas durante as discussões, mas, ainda assim, é possível direcionar a discussão, sugerindo insights sobre a importância e eficácia de certas ideias e de como elas se aplicam à equipe.

5. Identificar experiências e exemplos relevantes: Durante a discussão, compartilhar exemplos ou experiências que fazem parte de sua própria história pode ser um recurso muito eficaz. Experiências e exemplos são facilmente relembrados e favorecem uma percepção mais clara de como certos conceitos se aplicam na prática. Considerar a possibilidade de preparar uma ou duas experiências para expor durante a discussão, a fim de estabelecer conexões entre os tópicos da discussão e suas experiências reais.

6. Selecionar horário e local para a realização da discussão: Escolha um horário e um local apropriados para a reunião e certifique-se de que o espaço e os equipamentos necessários estarão disponíveis. Considerando a possibilidade de a discussão ocorrer durante uma reunião da equipe, ou até mesmo no horário de almoço. Lembre-se de que, apesar de os equipamentos para apresentação de slides estarem disponíveis para utilização durante as discussões, o uso desse recurso não é obrigatório. Muitos líderes acreditam que uma conversa informal, sem o uso de slides, ao redor de uma mesa onde toda a equipe está reunida, pode ser uma forma eficaz de discutir conceitos.

7. Personalizar o convite: O modelo de texto para o convite a ser enviado por e-mail, anexado a este documento, poderá ser personalizado, a fim de se ajustar, da melhor forma possível, a situações específicas.

Desta forma, ao liderar uma discussão, é provável que se utilize uma gama de questões investigativas, técnicas eficazes para ouvir e respostas encorajadoras para estimular e direcionar a discussão. Ao fim disso, é importante, ao concluir a discussão, encorajar os participantes a refletir a respeito das mudanças de atitude que eles terão, como resultado da discussão. A considerar também as sugestões apresentadas na seção "Próximos Passos" do 
roteiro, que têm o objetivo de direcionar os esforços dos participantes para a aplicação de novas ideias e abordagens no ambiente de trabalho. Assim como solicitar que os participantes sintetizem pontos e temas relacionados ao que aprenderam durante a discussão. Em paralelo, considerar a possibilidade de programar uma reunião posterior, a fim de dar continuidade à discussão ou comunicar-se com os participantes a respeito dos avanços que fizeram na aplicação de novas ideias e abordagens no ambiente de trabalho. Por fim, solicitar aos participantes que deem feedback sobre a discussão. Por exemplo, pergunte ao grupo, pessoalmente ou por e-mail, quais aspectos da discussão eles mais apreciaram e quais mudanças poderiam sugerir para o próximo.

\section{Considerações finais}

A partir da análise dos padrões comportamentais pesquisados, o sofrimento, em sua ampla diversidade de sentidos e expressões, não pode equiparar-se, unicamente, ao sofrimento psíquico. Algumas de suas manifestações se assemelham, enquanto outras possuem aspectos específicos. A acepção ampla do sofrimento como um bem do sujeito tem sido negligenciada, na atualidade, dificultando impulsionar o sujeito a uma ação transformadora, bem como a atuação da saúde coletiva, inclusive em termos interdisciplinares. Na gestão do trabalho, a ausência de reconhecimento dessa peculiaridade do sofrimento gera agravos, dificilmente identificados, à saúde dos trabalhadores.

Em linhas gerais, quebrar as lógicas e práticas que configuram uma dada compreensão do sofrimento que o transforma em adoecimento envolve a ampliação de um debate na busca de alternativas que possam propiciar enfoques diferenciados e espaços adequados para oferecer cuidados específicos às manifestações do sofrimento. Assim, a proposta de pesquisa proporciona alternativas que não conduzam aos destinos detectados no presente estudo, mas a novos percursos, com diferentes itinerários.

Assim, ser um líder exige autoconhecimento acima de tudo, pois conhecer suas fraquezas e fortalezas é o primeiro passo para gerir uma equipe que possui suas particularidades. Por conseguinte, o líder deve ser um agente de transformações, fonte de referência e inspiração e para conseguir influenciar as pessoas, mesmo em situação adversa. Ou seja, consegue estimular as pessoas a se adaptarem, fazendo com que consigam se transformar e gerenciar 
melhor as mudanças, reconhece as individualidades de cada indivíduo e procura atender as suas necessidades individuais.

\section{REFERÊNCIAS}

AMARANTE, Paulo. Saúde mental e atenção psicossocial. SciELO-Editora FIOCRUZ, 2007.

BERGAMINI, C. Whitaker, TASSINARI, Rafael. Psicopatologia do Comportamento Organizacional Organizações Desorganizadas, mas produtivas. São Paulo: Cengage Learning, 2008.

DA SILVA, Priscyla; LUIZ, Prof ${ }^{\circ}$ Mario. Liderança E Motivação No Ambiente Organizacional, 2011.

DEJOURS, Christophe. A loucura do trabalho: estudo de psicopatologia do trabalho. 5. ed. ampl. São Paulo: Cortez Ed., 1992.

DEJOURS, Christophe. Psicodinâmica do trabalho: contribuições da escola dejouriana à análise da relação prazer, sofrimento e trabalho. São Paulo (SP): Atlas, 1994.

ENRIQUEZ, Eugène. Vida psíquica e organização. Vozes, 2000.

FADIMAN, J., FRAGER, R. Teorias da personalidade. São Paulo, Harbra,1986.

GIL, Antonio. Como elaborar projetos de pesquisa. São Paulo, v. 5, n. 61, p. 16-17, 2002.

JÚNIOR, Osvaldo Gradella. Sofrimento psíquico e trabalho intelectual. Cadernos de Psicologia Social do Trabalho, v. 13, n. 1, p. 133-148, 2010.

LIMONGI-FRANÇA, Ana Cristina. Qualidade de vida no Trabalho - QVT: conceitos e práticas nas empresas da sociedade pós-industrial. 2. ed. São Paulo: Atlas, 2010.

MARGIS, R., at Al. Relação entre estressores, estresse e ansiedade; R. Psiquiatr. RS, 25' (suplemento 1): 65-74, abril 2003

MENDES, A. Magnólia. Psicodinâmica do trabalho: Teoria, método e pesquisas. São Paulo: Editora Gráfica, 2007.

RODRIGUES, Marcus Vinícius Carvalho. Qualidade de Vida no Trabalho: evolução e análise no nível gerencial. 8. ed. Petropólis, RJ: Vozes, 2001.

WAGNER, John. Comportamento organizacional-criando vantagem competitiva. Editora Saraiva, 2017. 